\title{
María Flórez-Estrada Pimentel, La notable maternidad de Luis Gerardo Mairena. Crisis y transformación de los lazos sociales en Costa Rica
}

\section{Elva Rivera Gómez ${ }^{1}$}

\author{
"el menor de cuatro meses estaba enfermo y tuve que auxiliarlo, \\ brindarle servicios médicos y medicación y cuidados, \\ y me fui encariñando con el menor y le dediqué todo mi tiempo, \\ ... le he dado durante todo este tiempo todo mi amor de padre-madre \\ y las cosas necesarias para que \\ crezca en un ambiente sano, bien alimentado y con estudios y recreación" \\ (Mairena, en Flórez-Estrada, 2017, p. 52).
}

La notable maternidad de Luis Gerardo Mairena. Crisis y transformación de los lazos sociales en Costa Rica de María Flórez-Estrada Pimentel, publicada por la Editorial de la Universidad de Costa Rica, en la colección Identidad Cultural del Centro de Investigación en Identidad y Cultura Latinoamericanas (CIICLA), es una obra que aborda el tema de la transmaternidad-paternidad y del proceso administrativo y judicial de un caso de adopción bajo la impartición de justicia y cultura costarricense heteronormativa neoliberal.

María Flórez-Estrada Pimentel sustenta su indagación en diversas fuentes. Una de ellas es la fuente judicial, pues recurre al expediente judicial 03-000712165-FA sobre el caso de adopción, para reconstruir el proceso administrativo y jurídico y demostrar las diversas aristas heteronormativas de la impartición de justicia. Otra fuente de gran valía consultada para esta investigación es la hemerográfica. La revisión de los diarios La Nación, Diario Extra y Al Día, de los años 2002-2010, le permitieron identificar los discursos institucionales, la opinión de ciertos sectores religiosos y conservadores en torno a la adopción del "caso Mairena" y al abuso sexual contra niñas y niños, conocido como pedofilia por parte de curas católicos en Costa Rica. Mediante las fuentes orales, en especial las entrevistas, logró recuperar las voces, identificar los silencios y entretejer las posturas de las personas implicadas en el proceso de abandono y adopción: la madre biológica (Yolanda), el personal judicial, del Patronato Nacional de la Infancia (PANI), las funcionarias profesionales, Mairena -fuente principal de la disertación-y de seis habitantes de Purral de Goicochea, conformado por tres grupos de edad de 18-33, 34-50 y de 51 y más.

1 Mexicana. Doctora en Historia y Estudios Regionales por la Universidad Veracruzana, México. Profesora e investigadora del Colegio de Historia de la Facultad de Filosofía y Letras de la Benemérita Universidad Autónoma de Puebla, México. Correo electrónico: elva.rivera@gmail.com 
María Flórez-Estrada Pimentel, la autora, en el capítulo 1 "Encargos sociales en busca de cuerpos" presenta una revisión historiográfica en torno a la familia, la maternidad moderna, la identidad nacional y el travestismo como expresión transgénero en Costa Rica. También recurre a la teoría feminista, en particular de la interpretación queer para analizar la maternidad y sus diversas connotaciones simbólicas, biológicas y culturales.

Flórez-Estrada Pimentel revisa los discursos falogocéntricos en torno al cuerpo y la sexualidad, la economía política sexual, el orden sexual hegemónico, los sistemas de género, la perfomatividad, la clasificación de los cuerpos a partir del sexo, género y raza, clase, entre otros, estudiados por Judith Butler, Gayle Rubín, Braudillard y otras autoras y autores. A partir de sus obras, revisa las interpretaciones históricas, filosóficas, psicológicas, antropológicas, jurídicas, médicas referentes a la sexualidad y al cuerpo, el "hermafroditismo" o intersexualidad y la adopción durante las tres últimas décadas en Costa Rica.

En el capítulo 2 "Perfil de Purral, Goicoechea", Flórez-Estrada Pimentel retoma el proyecto "Creación de entornos seguros", realizado por el gobierno costarricense conjuntamente con el Programa de las Naciones Unidas para el Desarrollo (PNUD) en los cantones de Belén, Aguirre, Montes de Oca, Goicoechea, Alajuelita, Escazú, Garabito y Pococí, entre los años 2005-2006. El estudio produjo diagnósticos de diez cantones, como por ejemplo, el caso del cantón de Goicoechea con un tejido social muy particular, advierte la autora.

Según el diagnóstico consultado por la autora, Purral, distrito de Goicoechea, tenía 317 tugurios, 274 viviendas precarias en todo el cantón, presentando vulnerabilidad geográfica, social y cultural en su población: marginación, analfabetismo, deserción escolar, violencia estructural y de género en las "amas de casa" de entre 20-44 años, consumo de drogas, el pandillerismo juvenil y prostitución infantil. Es decir, una radiografía de la región vulnerada por la economía global neoliberal, muy similar a las que se presentan en cada uno de los países de nuestro continente por tratarse de países periféricos.

En el capítulo 3 "Orfandades" la autora realiza una exhaustiva revisión de los discursos jurídicos en torno a la declaración de abandono y otorgamiento del depósito judicial definitivo de adopción del niño, en las leyes costarricenses y de los derechos humanos que protegen a la infancia a nivel internacional. La autora presenta el proceso judicial que enfrentó Mairena, que inició en septiembre de 2003, y concluyó en septiembre de 2004 a su favor. Es decir, se da cuenta que la(el) solicitante enfrentó dos procesos: uno administrativo y otro judicial para solicitar la declaratoria de abandono por parte de la madre y del padre biológico, y obtener el depósito definitivo con posibilidad de adopción.

Flórez-Estrada devela los obstáculos administrativos institucionales, la homofobia, y sobre todo, la interpretación de las leyes desde un punto de vista biologicista incapaz de reconocer la constitución de las familias derivadas de los efectos de la economía neoliberal; menos aún brindar las condiciones 
mínimas de protección a los menores de edad abandonados, y otorgar la adopción a una persona que se reconoce como transgénero.

La autora logra construir las redes sororales y alianzas femeninas que se entretejieron para el cuidado y el ejercicio del maternazgo simbólico de Mainera en el espacio público, ante la precariedad "individual, social y cultural" de la madre biológica que vulneró los derechos humanos del niño en disputa. Esas alianzas, Flórez-Estrada, las pudo construir a partir de los discursos de mujeres con una amplia apertura y aceptación a la condición transgenéro. Así, da visibilidad a la sororidad de la profesora del kínder, de la médica de la clínica, de la directora ejecutiva de PANI y de la jueza de familia.

Bajo una perspectiva foucaultina, la autora interpreta los discursos y prejuicios heteronormativos en torno a las indagatorias administrativas para demostrar la "factibilidad" de una maternidad transgénero, la ausencia de abuso sexual; y logra reconstruir los escenarios de las lógicas institucionales de los métodos y modelos decimonónicos dominantes en las ciencias psicológicas, médicas y jurídicas en los interrogatorios del proceso de adopción. A través del análisis de los fragmentos de la fuente judicial y de las entrevistas identifica los prejuicios heterosexuales dominantes en torno a las relaciones de parentesco, los cuidados maternos, la sexualidad y los contradiscursos en las personas e instituciones.

Finalmente en el capítulo 4 "La población de Purral habla sobre Mairena. Las sexualidades, la maternidad, la paternidad, la política y mucho más", María Flórez-Estrada Pimentel presenta el perfil sociodemográfico de la muestra de estudio. Así emergen las historias de Teresa, Jacinta, Rosa, José, Gonzalo y Fernando quienes dan cuenta de la desigualdad social, la marginación, la discriminación, los efectos de la cultura de la violencia y la drogadicción, de la deserción escolar, el trabajo infantil y juvenil, de los embarazos y maternidad en la población adolescente, de la paternidad ausente y las jefaturas femeninas, de la pederastia; en fin, relatos que descubren el otro rostro de la Costa Rica "feliz", el de la vida cotidiana y de la identidad nacional en crisis. La autora teje finalmente los relatos para mostrar la doble moral que se reproduce en una sociedad patriarcal en torno a la maternidad transgénero, los cuidados maternos, la homosexualidad, el matrimonio; es decir, la percepción biologicista de la cultura del cuidado, de la identidad y de la sexualidad.

Por último, a lo largo de la obra la autora logra su objetivo: explicar por qué el Estado y la sociedad conservadora apoyaron otorgar la custodia de un niño a una madre que no ocultó ni su condición de transgénero, a través de su perfomatividad travesti, ni su deseo homosexual, y le negaron la custodia a la madre biológica. El caso, analizado en la obra, pone en la mesa de la discusión a un Estado y a una sociedad que refuerza conceptos, modelos y normas jurídicas decimonónicas. Sin embargo, otra parte de esta (desde los derechos humanos) reconoce la igualdad jurídica de todas las personas 
más allá independientemente de su clase, raza e identidad sexual; y lo más importante, las reconoce jurídicamente en la práctica como lo pone de manifiesto Mainera: "Que las del Poder Judicial, de psicología y de trabajo social, no asimilaban que un trans pudiera dar amor a una persona o, en este caso, a un niño" (Mairena, 23 de febrero 2010, en Flórez-Estrada, 2017, p. 51).

La obra, La notable maternidad de Luis Gerardo Mairena. Crisis y transformación de los lazos sociales en Costa Rica, de María Flórez-Estrada Pimentel es una aportación a los estudios de la transmater-paternidad; utilizo este término para referirme al doble rol social y cultural de la crianza y educación de las y los hijos no biológicos por una persona que tiene una identidad sexual que transgrede el binarismo heteronormativo impuesto por la ciencia y la cultura institucional, social y cultural patriarcal.

\section{Referencias}

Braudel, Fernand. (1984). La Historia y las Ciencias Sociales. Madrid: Alianza Editorial.

Flórez-Estrada Pimentel, María. (2017). La notable maternidad de Luis Gerardo Mairena. Crisis y transformación de los lazos sociales en Costa Rica. San José: Editorial UCR. 